Western University

Scholarship@Western

$10-1-2020$

\title{
Proceedings of the 2019 Canadian Inflammatory Myopathy Study Symposium: Clinical Trial Readiness in Myositis.
}

\author{
Valérie Leclair \\ Océane Landon-Cardinal \\ Rohit Aggarwal \\ Nick Bansback \\ Craig Campbell \\ University of Western Ontario, craig.campbell@lhsc.on.ca
}

See next page for additional authors

Follow this and additional works at: https://ir.lib.uwo.ca/paedpub

Part of the Pediatrics Commons

Citation of this paper:

Leclair, Valérie; Landon-Cardinal, Océane; Aggarwal, Rohit; Bansback, Nick; Campbell, Craig; Feldman, Brian M; Jarry, Martin; McNamara, Suzan; White, Barbara; and Hudson, Marie, "Proceedings of the 2019 Canadian Inflammatory Myopathy Study Symposium: Clinical Trial Readiness in Myositis." (2020).

Paediatrics Publications. 531.

https://ir.lib.uwo.ca/paedpub/531 


\section{Authors}

Valérie Leclair, Océane Landon-Cardinal, Rohit Aggarwal, Nick Bansback, Craig Campbell, Brian M Feldman, Martin Jarry, Suzan McNamara, Barbara White, and Marie Hudson 


\title{
Proceedings of the 2019 Canadian Inflammatory Myopathy Study Symposium: Clinical Trial Readiness in Myositis
}

\author{
Valérie Leclair (D), Océane Landon-Cardinal, Rohit Aggarwal, Nick Bansback, Craig Campbell, \\ Brian M. Feldman, Martin Jarry, Suzan McNamara, Barbara White, and Marie Hudson, \\ for the CIMS Investigators
}

\begin{abstract}
The Canadian Inflammatory Myopathy Study (CIMS) is a multicenter prospective cohort recruiting in 8 centers across Canada. One of the aims of CIMS is to conduct and participate in clinical trials in autoimmune inflammatory myopathies (AIM). Conducting clinical trials in rare diseases such as AIM presents challenges. During this symposium, experts in the field presented different solutions to successfully conduct clinical trials in AIM, including the importance of collaboration and careful trial design, as well as training and mentoring of young investigators. (J Rheumatol First Release June 15 2020; doi:10.3899/jrheum.200480)
\end{abstract}

Key Indexing Terms:

POLYMYOSITIS

INCLUSION BODY MYOSITIS

\author{
DERMATOMYOSITIS \\ CLINICAL TRIALS
}

The Canadian Inflammatory Myopathy Study (CIMS) group held its second national symposium in Montreal, Canada, on December 6, 2019. The goal was to develop capacity to conduct and participate in clinical trials in autoimmune inflammatory myopathies (AIM). The meeting was organized by Drs. Marie Hudson (chair), Océane Landon-Cardinal, and Valérie Leclair. The event was attended by 11 rheumatologists, 1 neurologist, 1 pediatric rheumatologist, 1 pediatric neurologist, 1 neuropathologist, 1 respirologist, 1 physiotherapist, 1 nurse clinician, 2 patient research partners, 2 non-medical scientists, and 3 representatives of the pharmaceutical

From the Department of Medicine, McGill University; Division of Rheumatology, Jewish General Hospital; Department of Medicine, Université de Montréal; Division of Rheumatology and Research Center, Centre Hospitalier de l'Université de Montréal, Montreal, Canada; Division of Rheumatology and Clinical Immunology, Department of Medicine, University of Pittsburgh School of Medicine, Pittsburgh, Pennsylvania, USA; University of British Columbia and Arthritis Research Canada, Vancouver, British Columbia; Department of Pediatrics, London Children's Hospital; University of Western Ontario, London, Ontario; Faculty of Medicine and IHPME Dalla Lana School of Public Health, University of Toronto; Division of Rheumatology, The Hospital for Sick Children, Toronto, Ontario; Corbus Pharmaceutical Holdings Inc., Norwood, Massachusetts, USA; Lady Davis Institute, Montreal; Department of Medicine, Université de Laval; Division of Rheumatology, Centre Hospitalier Universitaire de Québec, Québec City; Montreal Neurological Institute, McGill University; Division of Rheumatology, Hôpital du Sacré-Coeur, Montreal, Québec, Canada.

As part of the supplement 2019 Canadian Inflammatory Myopathy Study Symposium, this report was reviewed internally and approved by the Guest Editors for integrity, accuracy, and consistency with scientific and ethical standards.

This symposium was funded by a Canadian Initiative for Outcomes in Rheumatology cAre (CIORA) grant and the McGill Interdisciplinary Initiative in Infection and Immunity, as well as unrestricted educational industry. The symposium was sponsored by a Canadian Initiative for Outcomes in Rheumatology cAre (CIORA) grant, the McGill Interdisciplinary Initiative in Infection and Immunity (MI4), and industry.

The CIMS cohort was inspired by a strong Canadian commitment to collaborative research in rheumatic diseases. It was created and enrolled its first subjects in 2014. This pan-Canadian multicentered prospective cohort has now recruited more than 230 AIM subjects from 8 sites across Canada. Data are collected annually and entered into a central database for the purpose of epidemiological and discovery research ${ }^{1,2,3,4,5}$. The next goal for the study group

\begin{abstract}
grants from Grifols, Corbus Pharmaceuticals, Bristol-Myers Squibb, Sanofi, and Pfizer.

V. Leclair, MD, Department of Medicine, McGill University, and Division of Rheumatology, Jewish General Hospital; O. Landon-Cardinal, MD, Department of Medicine, Université de Montréal, and Division of

Rheumatology and Research Center, Centre Hospitalier de l'Université de Montréal; R. Aggarwal, MD, MSc, Division of Rheumatology and Clinical Immunology, Department of Medicine, University of Pittsburgh School of Medicine; N. Bansback, PhD, University of British Columbia and Arthritis Research Canada; C. Campbell, MD, Department of Pediatrics, London Children's Hospital, University of Western Ontario; B.M. Feldman, MD, MSc, Faculty of Medicine and IHPME Dalla Lana School of Public Health, University of Toronto, and Division of Rheumatology, The Hospital for Sick Children; M. Jarry, Patient Advocate, Corbus Pharmaceutical Holdings Inc.; S. McNamara, PhD, Corbus Pharmaceutical Holdings Inc.; B. White, MD, Corbus Pharmaceutical Holdings Inc.; M. Hudson, MD, MPH, Department of Medicine, McGill University, and Division of Rheumatology, Jewish General Hospital, and Lady Davis Institute.

Address correspondence to Dr. V. Leclair, Division of Rheumatology, Jewish General Hospital, A.725-3755 Chemin de la Côte-SainteCatherine, Montreal, Quebec H3T1E2, Canada.E-mail:valerie.leclair@ mcgill.ca
\end{abstract}

Personal non-commercial use only. The Journal of Rheumatology Copyright $(\subset) 2020$. All rights reserved. 
is to develop capacity to conduct and participate in clinical trials in AIM.

Martin Jarry and Suzan McNamara, 2 patient advocates, opened the symposium. They emphasized the importance of patient advocacy in rare diseases and how this could shape the research agenda, even that of industry ${ }^{6}$. With an overall incidence of 8-18 cases/million/year and a prevalence of 14-30 cases $/ 100,000$, AIM is a rare disease ${ }^{7}$. At the moment, most industry-sponsored clinical trials in adult AIM do not include Canadian sites. Canadian patients with AIM are thus at a considerable disadvantage regarding early access to potentially novel therapeutic interventions. Yet Canada has strengths that could help attract industry, including a favorable exchange rate. The challenges of conducting clinical trials in Canada and possible solutions were examined throughout the symposium and are summarized in Table 1.

Collaboration facilitates translational research and accelerates access to clinical trials for patients with neuromuscular diseases. TREAT-NMD is an example of a global network in neuromuscular diseases offering an infrastructure to connect researchers, clinicians, patients, and industry worldwide ${ }^{8}$. The chair of the TREAT-NMD Global patient registry, Dr. Craig Campbell, outlined its multifaceted approach to clinical trials facilitation including training and education as well as guidance for study planning. The global registry also serves as a link to easily locate centers that could be sites for any given trial, benefiting both patients and industry. A key message from this session was that it is important for research groups to identify common goals and to build their network infrastructure around them, because a desire to cover too much ground can lead to failure.

Dr. Brian Feldman, a pediatric rheumatologist and clinician-researcher, shared his experience conducting clinical trials in AIM. The pediatric rheumatology community has been a leader in successful collaborative networks such as the Childhood Arthritis and Rheumatology Research Alliance (CARRA) and the Pediatric Rheumatology International Trials Organisation (PRINTO) and has played a major role in the International Myositis Assessment and Clinical

Table 1. Challenges of conducting autoimmune inflammatory myopathies (AIM) clinical trials in Canada.

\begin{tabular}{|c|c|}
\hline Challenge & Possible Solution \\
\hline Limited resources & $\begin{array}{l}\text { Consider innovative trial designs (e.g., } \\
\text { pragmatic trials, patient-centered outcomes). } \\
\text { Facilitate recruitment using established AIM } \\
\text { registries. }\end{array}$ \\
\hline Regulatory agencies & $\begin{array}{l}\text { Partner with regulators to develop and validate } \\
\text { outcome measures that meet their requirements. }\end{array}$ \\
\hline $\begin{array}{l}\text { Inexperienced } \\
\text { investigators }\end{array}$ & $\begin{array}{l}\text { Mentor young investigators to increase capacity. } \\
\text { Create and maintain easily accessible training } \\
\text { resources. }\end{array}$ \\
\hline $\begin{array}{l}\text { Complex outcome } \\
\text { measures }\end{array}$ & $\begin{array}{l}\text { Develop and validate AIM subset-driven } \\
\text { outcome measures that can be easily interpreted. }\end{array}$ \\
\hline
\end{tabular}

Study group. Those groups were key in developing outcome measures and standardizing treatments in juvenile dermatomyositis ${ }^{9,10,11}$. One of the main points of Dr. Feldman's presentation was the benefit of "thinking outside the box" when designing clinical trials in AIM. He presented alternative study designs and analytic methods such as pragmatic trials and the inverse probability of treatment weighting of observational data that are cost-effective and leverage existing research infrastructure ${ }^{12,13}$.

Dr. Rohit Aggarwal, an adult rheumatologist and clinician researcher, discussed trial design and outcome measures in AIM. He presented the strengths and limitations of the 2016 American College of Rheumatology/European League Against Rheumatism criteria for clinical response in dermatomyositis and polymyositis ${ }^{14}$. Notably, he discussed the pitfalls of the core set measures including the manual muscle testing (operator dependent, ceiling effect) and global activity visual analog scales (subjective, assessing several constructs at once). Dr. Aggarwal discussed newer outcome measures that could be easier to implement in a busy clinical practice such as physical activity monitors, physical function testing (e.g., Sit-to-Stand, 6-minute walk test, and timed up and go) as well as devices to obtain more objective measures of muscle strength, such as handheld dynamometers $)^{15,16}$. Dr. Aggarwal proposed the idea of a Myositis Clinical Trial Consortium that would have as a primary goal facilitating multicentered clinical trials in AIM. In a similar manner as TREAT-NMD, this consortium would facilitate planning and collaboration between different centers and would support clinical trial readiness by mentoring junior investigators, sharing standard operating procedure, and developing classification criteria/outcome measures.

Dr. Nick Bansback, a health economist, described emerging methods to co-design trials in collaboration with patients. The need for alternatives to traditional trial design has emerged from the increasing recognition that a lot of resources are invested in trials investigating treatments that many patients do not want, either through the treatment characteristics (mode of delivery, side-effect profile) or trial outcomes that are not sufficient to guide a patient's treatment decisions. In AIM, where patients and resources are scarce, patient-centered approaches could ensure optimal management of resources. While patient-reported outcomes are important and of interest for regulatory agencies, they do not always reflect patient preferences or priorities. Dr. Bansback explained the basis of patient-centered trial designs using examples from studies in rheumatoid arthritis and systemic sclerosis $^{17,18}$

Finally, Dr. Barbara White, chief medical officer for Corbus Pharmaceuticals, gave an industry perspective on conducting clinical trials in rare diseases. Dr. White acknowledged the need for new treatments in AIM, but pointed out that the rarity of the disease, the lack of consensus on classification criteria, and the complexity of the outcome measures

Personal non-commercial use only. The Journal of Rheumatology Copyright @ 2020 . All rights reserved. 
were major challenges for industry sponsors as well as regulators. Dr. White emphasized that well-trained and committed site investigators and research personnel were key to raising industry interest and conducting successful trials. The importance for the AIM community to develop valid outcome measures that are meaningful to the patient and regulatory agencies was also discussed.

Some main points should be considered to achieve clinical trial readiness in AIM. First, collaboration was mentioned throughout the presentations and the speakers gave several examples of successful networks facilitating clinical trials in rare diseases. Second, planning and trial design, both traditional and innovative, were mentioned as crucial for successful clinical trials. Third, training and mentoring young investigators to provide them with the tools to meet sponsors' expectations and encourage them to invest in research were deemed to be essential.

\section{ACKNOWLEDGMENT}

CIMS investigators: Alexandra Albert, Antonio Avina-Zubieta, Pari Basharat, Josiane Bourré-Tessier, May Choi, Paul Fortin, Marvin Fritzler, Sabrina Hoa, Kun Huang, Marie Hudson, Stephanie Keeling, Océane Landon-Cardinal, Maggie Larché, Valérie Leclair, Nancy Maltez, Ariel Masetto, Ines Midzic, Cecile Phan, Annaliese Tisseverasinghe, Fergus To, Shannon Vennance, and Évelyne Vinet.

\section{REFERENCES}

1. Leclair V, Regardt M, Wojcik S, Hudson M, (CIMS). Health-related quality of life (HRQOL) in idiopathic inflammatory myopathy: A systematic review. PLoS One 2016;11:e0160753.

2. Greenfield J, Hudson M, Vinet E, Fortin PR, Bykerk V, Pineau CA, et al. A comparison of health-related quality of life (HRQOL) across four systemic autoimmune rheumatic diseases (SARDS). PLoS One 2017;12:e0189840.

3. Bangert E, Hudson M, Vinet E, Wang M, Gyger G. Nailfold videocapillaroscopy in idiopathic inflammatory myopathies [abstract]. J Rheumatol 2018;45:1024.

4. Maliha PG, Hudson M, Abikhzer G, Singerman J, Probst S. 18F-FDG PET/CT versus conventional investigations for cancer screening in autoimmune inflammatory myopathy in the era of novel myopathy classifications. Nucl Med Commun 2019; 40:377-82.

5. Assayag D, Hirsch A, Baron M, Vinet E, Albert A, Fortin P, et al. Extensive interstitial lung disease in inflammatory myopathy is a strong predictor of mortality. European Respiratory Society International Congress, 2017; Milan, Italy. Eur Respir J 2017;50 Suppl 61:PA890.
6. McNamara S. Chronic myeloid leukemia. [Internet. Acessed May 21, 2020.] Available from: www.cmleukemia.com/ suzan-mc-namara-and-the-petition.html

7. Leclair V, Bernatsky S, Hudson M. Myositis: an inclusive guide to the inflammatory myopathies. London: Jaypee Brothers; in press.

8. Rodger S, Lochmüller H, Tassoni A, Gramsch K, König K, Bushby $\mathrm{K}$, et al. The TREAT-NMD care and trial site registry: an online registry to facilitate clinical research for neuromuscular diseases. Orphanet J Rare Dis 2013;8:171.

9. Giancane G, Lavarello C, Pistorio A, Oliveira SK, Zulian F, Cuttica $\mathrm{R}$, et al. The PRINTO evidence-based proposal for glucocorticoids tapering/discontinuation in new onset juvenile dermatomyositis patients. Pediatr Rheumatol Online J 2019;17:24.

10. Ruperto N, Ravelli A, Pistorio A, Ferriani V, Calvo I, Ganser G, et al. The provisional Paediatric Rheumatology International Trials Organisation/American College of Rheumatology/European League Against Rheumatism disease activity core set for the evaluation of response to therapy in juvenile dermatomyositis: a prospective validation study. Arthritis Rheum 2008;59:4-13.

11. Huber AM, Robinson AB, Reed AM, Abramson L, Bout-Tabaku $\mathrm{S}$, Carrasco R, et al. Consensus treatments for moderate juvenile dermatomyositis: beyond the first two months. Results of the second childhood arthritis and rheumatology research alliance consensus conference. Arthritis Care Res 2012;64:546-53.

12. DeWitt EM, Brunner HI. The landscape of comparative effectiveness research in rheumatology. Nat Rev Rheumatol 2014;10:57-62.

13. Weinfurt K. Living textbook of pragmatic clinical trials. [Internet Accessed May 21, 2020.] Available from: rethinkingclinicaltrials. org/chapters/pragmatic-clinical-trial/what-is-a-pragmatic-clinical-trial

14. Aggarwal R, Rider LG, Ruperto N, Bayat N, Erman B, Feldman BM, et al. 2016 American College Of Rheumatology/European League Against Rheumatism criteria for minimal, moderate, and major clinical response in adult dermatomyositis and polymyositis: an international myositis assessment and clinical studies group/ paediatric rheumatology international trials organisation collaborative initiative. Ann Rheum Dis 2017;76:792-801.

15. Bachasson D, Landon-Cardinal O, Benveniste O, Hogrel JY, Allenbach Y. Physical activity monitoring: a promising outcome measure in idiopathic inflammatory myopathies. Neurology 2017;89:101-3.

16. Kocoloski A, Ward C, Koontz D, Oddis C, Aggarwal R. Functional measures and patient home self-assessments in the idiopathic inflammatory myopathies. Arthritis Rheum 2017;69 Suppl 10:2171.

17. Bansback N, Keystone E, O'Dell J, Phibbs CS, Hannagan K, Brophy M, et al. Making smart investment decisions in clinical research. Trials 2015;16:590.

18. Harrison M, Spooner L, Bansback N, Milbers K, Koehn C, Shojania K, et al. Preventing rheumatoid arthritis: preferences for and predicted uptake of preventive treatments among high risk individuals. PLoS One 2019;14:e0216075. 